\title{
Longitudinal Relations Between Forgiveness and Conflict Resolution in Marriage
}

\author{
Frank D. Fincham \\ Florida State University
}

\author{
Steven R. H. Beach \\ University of Georgia
}

\author{
Joanne Davila \\ Stony Brook University
}

\begin{abstract}
Does forgiveness predict later conflict resolution in married couples? Twelve-month follow-up data on conflict resolution were collected from the couples studied by F. D. Fincham, S. R. Beach, and J. Davila (2004), who had provided earlier reports of forgiveness and conflict resolution. For wives, the positive dimension of forgiveness or benevolence predicted husbands' later reports of better conflict resolution controlling for initial levels of conflict resolution. This finding was independent of wives' marital satisfaction and the degree of hurt engendered by husbands' transgressions. For husbands, the only predictor of wives' reports of later conflict resolution was initial level of conflict resolution. The findings are discussed in terms of the direction of effect between forgiveness and conflict resolution and of the mechanisms that might link them.
\end{abstract}

Keywords: forgiveness, conflict resolution, marital satisfaction

Conflict resolution is integral to a successful relationship, and it is likely that resentment engendered by partner transgressions may fuel couple conflict and impede successful conflict resolution. In contrast, forgiving the partner for the transgression is a potential means of providing closure with regard to a painful or disturbing relationship event and reducing the extent to which that event can intrude upon future interactions. Thus, one might legitimately ask whether the spouse's failure to forgive earlier partner transgressions is related to the current use of ineffective conflict strategies in the relationship. In the absence of forgiveness, current disagreements or conflicts may trigger renewed feelings of transgression or prompt renewed retaliation or withdrawal. Forgiveness may therefore have substantial implications for long-term relationship outcomes as well as shortterm patterns of interaction. Specifically, when one partner opts out of the coercive cycle of reciprocal negative interaction, the other should be less likely to continue his or her negative behavior as well. In sum, forgiveness may provide one means to short-circuit the use of ineffective conflict strategies likely to emerge from the smoldering embers of an unforgiven transgression.

Fincham, Beach, and Davila (2004) have offered a de-

Frank D. Fincham, Family Institute, Florida State University; Steven R. H. Beach, Department of Psychology, University of Georgia; Joanne Davila, Department of Psychology; Stony Brook University.

Correspondence concerning this article should be addressed to Frank D. Fincham, Family Institute, Sandels Building, Florida State University, Tallahassee, FL 32306-1490. E-mail: ffincham@ fsu.edu tailed exposition of the above argument and have provided evidence to support it. In doing so, these authors observed that common to various approaches to forgiveness is the idea of a transformation in which negative motivation (e.g., to seek revenge, withdraw) toward the harm-doer is lessened. They went on, however, to argue that equally important for forgiveness is the development of a positive or benevolent motivational state toward the harm-doer (for a more complete account of this conceptualization of forgiveness, see Fincham, 2000). Drawing on this bidimensional view of forgiveness, they showed that husbands' reports of better conflict resolution were predicted by wives' increased positive, benevolence motivation across two studies. However, wives' reports of better conflict resolution were predicted by the negative dimension of husbands' forgiveness. An important finding is that for both wives and husbands, these associations were independent of the spouses' levels of marital satisfaction. The documentation of these crosssectional associations, however, begs the question of whether similar longitudinal associations exist that would provide stronger support for the causal inferences implicit in the above argument. Therefore, in the present study, we examine whether forgiveness predicts later reports of conflict resolution. It was hypothesized that a spouse's report of forgiving the partner's transgressions would be inversely associated with the partner's reports of ineffective conflict resolution 12 months later.

\section{Participants}

Method

Participants were a subsample of the 96 couples recruited by Fincham et al. (2004). They were recruited through 
advertisements and from a local middle school. Four hundred letters were mailed to families of eighth-grade daughters in a local middle school. Families were instructed to return a postage paid postcard if they were interested in participating. Seventy-seven postcards were returned (19\%). Of them, 31 families who were eligible participated. Advertisements were also placed in local newspapers, on cable television, and in the community. Interested families were asked to call the project. Two hundred forty-eight families were interested; of them, 65 who were eligible participated. Eligibility criteria included being a two-parent family with an eighth-grade daughter with the ability to read and comprehend questionnaires and participate in computer tasks. Families with daughters with moderate or severe learning disabilities that would impair their performance were excluded. Husbands were 43.2 years old on average $(S D=4.2)$ and predominantly Caucasian $(97 \%)$. Of the husbands, $45 \%$ reported graduating high school, and $55 \%$ reported a college or postgraduate education. Wives were 41.1 years old on average $(S D=4.7)$ and predominantly Caucasian (98\%). Of the wives, $40 \%$ reported graduating high school, and $57 \%$ reported a college or postgraduate education. Median family income was in the range of $\$ 51,000-\$ 60,000$.

\section{Procedure and Measures}

Participating families attended a laboratory session. During this time, spouses completed measures of marital quality, ineffective arguing, and forgiveness. Twelve months later, families were again contacted and scheduled for a laboratory visit. Two families had moved out of state, two families could not be contacted, and six families declined to participate, leaving a follow-up sample of 86 families that did not differ from nonparticipating families on any demographic variables. Families were paid $\$ 75$ for each visit.

Marital satisfaction. The Marital Adjustment Test (MAT; Locke \& Wallace, 1959) is a frequently used measure of marital quality. Locke and Wallace (1959) reported split-half reliability of .90 and that the MAT discriminated between couples "judged to be exceptionally well-adjusted in marriage by friends who knew them well" and participants who "were known to be maladjusted in marriage" (p. 254). The MAT also correlates with clinicians' judgments of marital discord (Crowther, 1985). Across all items, the MAT had Cronbach alphas of .79 for husbands and .71 for wives, respectively.

Conflict resolution. Conflict resolution was assessed with the Ineffective Arguing Inventory (Kurdek, 1994). This measure was based on descriptions of ineffective arguing found in marital research. It comprises eight items (e.g., "Our arguments are left hanging and unresolved") that spouses rate to indicate the extent to which they characterize their relationship. Kurdek (1994) reported high internal consistency for the measure when completed by gay, lesbian, and heterosexual couples (alpha ranges from .86 to .89) and sizable correlations with relationship satisfaction $(r=-.62$ to -.71$)$. In this study, comparable alpha coefficients of .84 and .88 were obtained for husbands and wives, respectively. Moreover, Kurdek reported that the scale was stable over a 1 -year period ( $r=.63$ to .84 ), and this study yielded similar stability coefficients $(.80$ for wives and .63 for husbands, respectively). Higher scores on this inventory reflect poorer conflict resolution. Two husbands and one wife did not provide usable data on this measure at Time 2 and were not used in the analyses.

Forgiveness. Forgiveness was assessed in relation to a transgression that occurred in the past 6 months of the initial visit in which the spouse felt "upset, angry, or hurt" by something their partner said or did. The respondent was asked to recall the event and describe it to the research assistant in as much detail as possible. They then rated the amount of hurt that they experienced. On a 9-point scale ranging from very little hurt to most hurt ever felt, husbands averaged $4.7(S D=2.0)$, and wives averaged $5.8(S D=$ 2.3). Participants also rated nine statements concerning possible negative/unforgiving or benevolent responses (negative responses: "I gave him/her the cold shoulder," "I withdrew from my partner," "I didn't want to have anything to do with her/him," "I did something to even the score," "I found a way to make her/him regret it," and "I retaliated or did something to get my own back"; benevolent responses: "I soon forgave my partner," "I am able to act as positively toward my partner now as I was before it happened," and "It was easy to feel warmly again toward your partner"). They indicated their ratings on a 6-point scale anchored by strongly agree at one end and strongly disagree at the other. Five husbands failed to provide useable information on this measure and were therefore excluded from the analyses. For the negative or unforgiveness dimension, coefficient alpha was .83 and .78 for wives and husbands, respectively. Analogous coefficients for the positive or benevolence dimension were .77 and .79 , respectively.

\section{Results}

The correlations among the variables are shown in Table 1. To examine longitudinal associations in a multivariate context, we conducted regression analyses for husbands and for wives in which partner reports of ineffective conflict resolution at 12 months were predicted from own marital satisfaction, initial level of conflict resolution, and initial self-reports of benevolence and unforgiveness. These regression analyses revealed that wives' self-reported benevolence was the only forgiveness dimension that uniquely predicted husbands' reports of ineffective conflict resolution 12 months later, $\beta=-.24, t(79)=-2.09, p<.05$. However, it could be argued that this finding is merely a function of the seriousness of the transgression selected by participants, and hence we recomputed this regression equation with the degree of hurt engendered by the transgression as an additional predictor variable. Benevolence remained a significant predictor, $\beta=-.23, t(79)=-2.03, p<.05$. For husbands, the only significant unique predictor of wives' reports of later ineffective conflict resolution was initial level of conflict resolution. 
Table 1

Correlations Among Variables for Husbands (Above Diagonal) and Wives

\begin{tabular}{|c|c|c|c|c|c|c|c|}
\hline Variable & 1 & 2 & 3 & 4 & 5 & $M$ & $\overline{S D}$ \\
\hline 1. Partner reported ICR at $\mathrm{T} 1$ & - & $.80^{* * *}$ & $-.35^{* *}$ & $.48^{* * *}$ & $-.47^{* * *}$ & 2.3 & 0.80 \\
\hline 2. Partner reported ICR at $\mathrm{T} 2$ & $.63^{* *}$ & - & $-.25 *$ & $.31^{* *}$ & $-.35^{* * *}$ & 2.2 & 0.88 \\
\hline 3. Benevolence & $-.36^{* *}$ & $-.45^{* *}$ & - & $-.53^{* *}$ & $.32^{* *}$ & 5.1 & 1.0 \\
\hline 4. Unforgiveness & .16 & $.20^{*}$ & $-.59^{* *}$ & - & $-.40^{* *}$ & 9.9 & 4.3 \\
\hline 5. Marital satisfaction & $-.35^{* * *}$ & $-.39^{* * *}$ & $.39^{* *}$ & $-.24^{*}$ & - & 116.0 & 21.1 \\
\hline$M$ & 2.3 & 2.2 & 5.2 & 8.31 & 118.7 & - & \\
\hline$S D$ & 0.69 & 0.72 & 0.92 & 4.45 & 19.1 & & - \\
\hline
\end{tabular}

Note. $\quad$ ICR $=$ ineffective conflict resolution; $\mathrm{T} 1=$ Time $1 ; \mathrm{T} 2=$ Time 2 .

${ }^{*} p<.05 .{ }^{* *} p<.01$.

\section{Discussion}

The current investigation builds on Fincham et al.'s (2004) documentation of a concurrent association between forgiveness and conflict resolution by showing that this relationship is also found longitudinally, at least for wives. Specifically, wives who endorsed lower benevolence in response to partner transgressions had husbands who reported higher levels of ineffective arguing 12 months later. This finding suggests that erosion of good will toward the partner is likely to undermine processes, such as accommodation (responding positively to a negative partner behavior), and allow negative responses to predominate during disagreements (Rusbult, Yovetich, \& Verette, 1996). The emergence of this effect 12 months later helps to rule out potential artifacts, such as mood or response bias, that might contribute to concurrent relationships. We find it important that this result was independent of initial levels of ineffective arguing, marital satisfaction, and degree of hurt engendered by the transgression. Thus, a number of plausible alternative explanations for this longitudinal association were ruled out. The lack of longitudinal findings for husbands no doubt reflects the high level of stability in wives' reports of ineffective arguing $(r=.80)$, which leaves little reliable variance to explain in wives' later reports once initial reports are controlled.

The documentation of a longitudinal association between forgiveness and conflict resolution for wives raises two obvious questions. First, what is the mechanism that links them? Although the addition of a temporal dimension comes closer to supporting causal inference, longitudinal data are still correlational, and so we can only speculate why low levels of benevolence among wives might play an important role in the way couples manage conflict. One possibility is that lack of benevolence motivation among wives increases the likelihood of using a negative start-up (responding to partner neutral affect with negative affect; Gottman, 1998) and/or decreases willingness to accommodate to negative partner behavior. Alternatively, unresolved partner transgressions may lead to frequent cognitive rehearsals of the transgression, thereby potentially increasing the strength of the connection between the partner and negative responses. Over time, this could lead to the partner automatically eliciting these reactions, particularly in the context of conflict, leading to more intense responses and more rapid escalation of conflict. In any event, promoting more effective conflict resolution may be facilitated to the extent that we better understand not only the nature of the association between forgiveness and relationship satisfaction but also the processes that promote forgiveness of partner transgressions.

Second, what is the direction of effect between forgiveness and conflict resolution? Our inability to examine this question represents an important limitation of the present study. Although we have focused on the potential impact of forgiveness on conflict and ruled out confounds related to concurrent measurement, general relationship satisfaction, and degree of hurt engendered by the transgression, it is plausible that the presence of unresolved conflict makes it harder to forgive the partner, reversing the causal flow hypothesized in the current investigation. In particular, the presence of unresolved conflict may inhibit empathy or willingness to accommodate, decreasing all facets of forgiveness. Likewise, ongoing unresolved conflict could undermine felt commitment, feeding back to maintain lower levels of benevolence and potentially higher levels of retaliation and withdrawal.

The potential for reciprocal effects and causal feedback loops between forgiveness and ineffective arguing suggests the possibility of more complex models than those tested by the current design. Given the potential for feedback loops of this sort to produce substantial and sometimes discontinuous change (Fincham, Stanley, \& Beach, 2007), future work that allows examination of reciprocal effects will be important. An additional limitation of the present study is that the homogeneous sample does not allow us to examine cultural context, as it may influence forgiveness processes. In view of the diversity of lay conceptions of forgiveness, it is particularly important to investigate the forgiveness processes cross-culturally as well as in particular subcultural contexts in the United States. One might expect, for example, that regional or ethnic variation in adherence to gender role norms, or differing expectations and definitions regarding forgiveness, might make some forgiveness processes more salient than others. Likewise, it may be that some types of transgressions are linked to particular patterns of nonforgiveness and may require special attention. Such nuances in the forgiveness-conflict connection seem par- 
ticularly likely to vary as a function of such subcultural contexts.

The findings also need to be viewed in the context of two further limitations. First, the attempt to control for transgression severity is less than optimal, as retrospective reports of hurt may be influenced by degree of forgiveness. An alternative - using trained coders to rate transgression severity-provides a different perspective, as illustrated by Fincham, Jackson, and Beach (2005), who obtained different findings for insider and outsider perspectives on transgression severity. Second, the operationalization of unforgiveness in this study, and in the forgiveness literature more generally, includes items conceptually similar to constructs (e.g., stonewalling) found in behavioral studies of marital interaction. This raises a question regarding the extent to which forgiveness provides a unique element to models of marriage.

In summary, the present results add to an emerging body of data to support attention to forgiveness in working with couples and thereby have a role to play in recent forgiveness interventions that integrate research, theory, and clinical experiences in working with couples (e.g., Gordon, Baucom, \& Snyder, 2005). Indeed, because anger has been shown to decline following a forgiveness intervention (e.g., Freedman \& Enright, 1996), the current results should encourage efforts to develop forgiveness interventions that might be tested as precursors to marital therapy when anger and resentment related to past partner transgressions are central to the presenting problem. At the same time, the different pattern of effects for husbands and wives suggests the possibility that forgiveness may function somewhat differently, on average, as a function of gender, and so particular facets may be targeted differently for husbands and wives in forgiveness interventions. Better understanding the gendered context of forgiveness will also be an important goal of future research.

\section{References}

Crowther, J. H. (1985). The relationship between depression and marital adjustment: A descriptive study. Journal of Nervous and Mental Disease, 173, 227-231.

Fincham, F. D. (2000). The kiss of the porcupines: From attributing responsibility to forgiving. Personal Relationships, 7, 1-23.

Fincham, F. D., Beach, S. R., \& Davila, J. (2004). Forgiveness and conflict resolution in marriage. Journal of Family Psychology, 18, 72-81.

Fincham, F. D., Jackson, H., \& Beach, S. R. H. (2005). Transgression severity and forgiveness. Journal of Social and Clinical Psychology, 24, 860-875.

Fincham, F. D., Stanley, S., \& Beach, S. R. H. (2007). Transformative processes in marriage. Journal of Marriage and the Family, 69, 275-292.

Freedman, S. R., \& Enright, R. D. (1996). Forgiveness as an intervention goal with incest survivors. Journal of Consulting and Clinical Psychology, 64, 983-992.

Gordon, K., Baucom, D. H., \& Snyder, D. K. (2005). Forgiveness in couples: Divorce, infidelity, and couples therapy. In E. L. Worthington (Ed.), Handbook of forgiveness (pp. 407-422). New York: Routledge.

Gottman, J. M. (1998). Psychology and the study of marital processes. Annual Review of Psychology, 49, 169-179.

Kurdek, L. (1994). Conflict resolution styles in gay, lesbian, heterosexual nonparent, and heterosexual parent couples. Journal of Marriage and the Family, 56, 705-722.

Locke, H. J., \& Wallace, K. M. (1959). Short marital adjustment prediction tests: Their reliability and validity. Marriage and Family Living, 21, 251-255.

Rusbult, C. E., Yovetich, N. A., \& Verette, J. (1996). An interdependence analysis of accommodation processes. In G. J. O. Fletcher \& J. Fitness (Eds.), Knowledge structures in close relationships: A social psychological approach (pp. 63-90). Mahwah, NJ: Erlbaum.

Received May 9, 2006

Revision received August 29, 2006

Accepted August 31, 2006 